\title{
Sobre el Derecho a la Secesión en la Independencia de Montenegro
}

\section{Teorías de la Secesión: Una Introducción}

La secesión es probablemente uno de los temas que mayor discusión genera en la doctrina internacionalista y políico-filosófica actual, por cuanto se ha constituido en prácricamente el único mecanismo para la modificación de fronteras internacionales, ya sea mediante la creación de nuevos Estados o la integración o asociación con otro preexistente. Como no cabe duda que la secesión se presenta regularmente en un contexto fáctico que hace difícil pensar que el Derecho sea capaz de prohibirla de manera efectiva en caso que los individuos deseen fuertemence la separación, es que se requiere de una mejor comprensión teórica de este fenómeno, de forma que luego tales conclusiones puedan verse reflejadas de algún modo en una práctica pacífica de la prerrogativa. De alli que los autores dividan aguas en torno a su legirimidad y a las causales que permitirian fundarla, al menos desde la perspectiva del deber ser, para así llegar a articular un derecho a la secesión conforme a los principios de un Estado liberal contemporáneo que no sólo parezca lógico en el papel, sino que también llegue a justificar su aplicación en la realidad juridica internacional.

De forma preliminar, bueno es aclarar qué entenderé por secesión. En términos generales, cuando hablo de secesión, ałudo a un acco de auroalienación de un conjunto de

"Fresado de Derecho y Ayudante del Departumento de Derecho I'ublico, Facultad de Ciencias huridicas y Saciales, Universidad de Concepción. 2006. individuos que se encuentran asociados a orra entidad total o parcialmente polícica, sustrayéndose de su autoridad, usualmente junto al territorio en el cual tesiden. Fste concepto, que es el que manejaré en su mayor parte de aqui en adelante, corresponde a una noción amplia del fenómeno secesionista, indusiva canto de aquella scparación con vocación independentista, así como de aquéllas que pretenden la incorporación en un Estado ya existente o la libre asociación con éste. En este sentido, muy pertinentes son las palabras de Linda Bishai, quien señala que "los origenes de la raiz [del término secesión] 
presuponen que la acción es becha unilateralmente por el individuo': se-ceder o 'auto ${ }^{2}$-cesión'. Al separarse, uno se retira de un grupo; uno no causa el retiro de otros" ${ }^{3}$. El sujeto pasivo, valga decir, el Estado que soporra la secesión, no riene injerencia en el proceso mismo; en caso contrario, la definición admiziría la posibilidad de expulsión (o técnicamente de cesión), lo que no realiza, razón por la cual sólo se puede hablar de un acto voluntario del grupo que ha decidido separarse, que he llamado acto de autoalienación.

En el actual sistema internacional, la secesión no encuentra regulación expresa, lo que no significa que ésta sea un tópico de baja importancia para la comunidad internacional, como ya he indicado. Esta situación ya es advertida al respecto por Aleksandar Pavković, quien señala que "[n] o hay, en la actualidad, cuerpo de derecho internacionalo doméstico el cual nos diga bajo cuáles circunstancias un intento de secesión estaria permitido o prohibido m. Para determinar la legitimidad de la secesión en el orden internacional es que la doctrina ha realizado diversas aproximaciones en cuanto a fa moralidad y oportunidad de ejercicio de un derecho a la secesión.

Quien realiza el estudio más certero en cuanto al contenido de las teorías normativas del fenómeno secesionista es, a mi juicio, Allen Buchanan, el cual distingue entre tcorías del derecho remedio y teorías de derecho primario. Atendiendo a las características que poseen los individuos que pretenden separarse, distingue en esta última categoría entre teorías adscriptivas y asociativas ${ }^{5}$. Estos enfoques realizados por Buchanan han sido acogidos en su mayor parte por la doctrina internacional, la que sólo ha variado en la nomenclatura, estableciendo tres teorías coincidentes en su sustancia con las señaladas. Así, se habla de teorías de la causa justa (just - cause theories, teoría de la secesión remedio, según Buchanan), teorías de la autodeterminación nacional (national self - determination theory, teorías adscriptivas del derecho primario a la secesión) y teorías de la elección (choice theories, teorias asociativas del derecho primario a la secesión).

\section{A. Teorias del Derecho Remedio a la Secesión}

Dentro de éstas es posible percibir diversos matices en cuanto a las circunstancias que han de hacer admisible una secesión en el orden internacional, pero todas tienen

\footnotetext{
Para mayor exactitud, e] vocabln que he traducido aqui como "individuo" es expresión del inglés "self". El socablo "anto" de esta craducción es expresión del inglés "self".

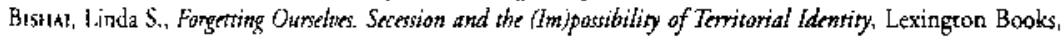
Lanham, Estados Unidos, 2004, p. 18. Esta idea es reirerada también en ia noción misma de aucodeterminación (de cuya dimensión excerna forma parte la secesión). Los sujctos se "deserminan" a si mismos, no son determinados

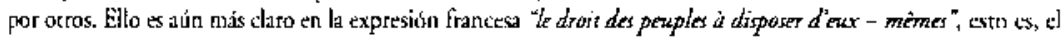
derecho de los pucbtos a disponer de sí mismos, tracándose por tanto la secesión de un derecho de aurodisposición en su grado externo y máximo.

4 Pavković, Aleksandar, "Explanatory Theories of Secession" (Manuscript), Macquarie Lniversity, Sydney, Australia, 2006. Agradezco al Profesor Parković la gentileza de compartir conmigo este trabajo antes de su publicación como parte de su próximo libro sobre el tema de la secesión.

5 Buculanan, Allen. "Theories of Secession", en Philosophy br Public Affairs, P'tifceton University Press, Volumen 26, No 1, Invierno 1997, pp. 3I-61, p. 34.
} 
en común la circunstancia de que la secesión será un derecho de último recurso; siguiendo a Margiotta, la secesión será "el último derecho" del sistema de derechos fundamentales ${ }^{6}$.

Estas teorías afirman que un grupo de individuos tendrá un derecho general a la secesión sólo si ha sufrido ciertas injusticias ${ }^{7}$. Una teoría de la secesión como derecho de última ratio obliga a que en todo proceso secesionista exista una característica esencial: la opresión por parte del Estado gobernante. En este supuesto, la secesión que no esté motivada por una política opresiva del Estado que utiliza la tiranía como mecanismo para gobernar, jamás estará justificada. La graduación de las causas opresivas que justifican la secesión son variables de acuerdo a los autores. Puede tratarse de injusticias presentes o pasadas (como violación sistemática de los derechos humanos de un conjunto de individuos), que todavía no han sido reparadas, la implementación de políticas redistributivas discriminatorias o la adquisición contraria a derecho del territorio en que residen los secesionistas en comento, por nombrar algunas ${ }^{8}$.

La teoría de la secesión último recurso de Buchanan no es tan absoluta, sino que se flexibiliza en ciertas circunstancias. Los planteamientos generales de la teoría responden a una secesión general, pero en determinadas circunstancias podrán existir derechos a la secesión especiales. Tales son los casos en que un Estado concede a parte de su población un derecho a la secesión; o bien la Constitución del Estado incorpora el derecho a la secesión'; o el acuerdo por el cual el Estado se fundó incluye expresa o implícitamente un derecho a la secesión en un futuro ${ }^{10}$. Esta flexibilización de la teoría no parece, en mi opinión, ser tal. Los derechos a la secesión especiales son una interferencia de las teorías asociativas, dado que la decisión de los afectados es la que se tomará en consideración, en última instancia, para determinar si se produce la separación. Que el derecho sea concedido, constitucionalizado o acordado respecto del Estado gobernante sólo facilita la situación en la praxis, ya que establece claramente

6 Véase Margiotta, Costanza, L'Ultimo Diritto. Profili Storici e Teorici della Secessione, Colección Il Mulino Ricerca, Società Edirrice Il Mulino, Bolonia, Italia, 2005, p. 15.

7 Buchanan, Allen, “Theories...", p. 34.

$s$ Véase Buchanan, Allen, "Toward a Theory of Secession", en Ethics, The University of Chicago Press, Volumen 101, No 2, Enero 1991, pp. 322-342, pp. 329-332. Recomendable respecto de la justicia distributiva en relación con la secesión es el trabajo de Christiano, Thomas, "Secession, Democracy and Distributive Justice", en Arizona Law Review, Volumen 37, No 1, Primavera 1995, pp. 65-72.

- Por extraño que parezca, diversos Estados consagraban, e incluso consagran, un derecho a la secesión. Como ejemplo, lo hicieron en su momento las Constituciones de la Unión Soviética, Birmania (hoy Myanmar) y de Serbia y Montenegro. Hoy, dichas cláusulas de secesión se encuentran en los textos fundamentales de Etiopía y de San Cristóbal y Nevis, como volveré a señalar más adelante. Un excelente trabajo a favor de la consagración y regulación por la vía constitucional del derecho a la secesión se puede encontrar en WEINSTock, Daniel, "Constitutionalizing the Right to Secede", en The Journal of Political Philosophy, Blackwell Publishers, Volumen. 9, No 2, junio 2001, pp. 182-203. Para una opinión en contrario, véase Sunstein, Cass R., "Constitutionalism and Secession", en The University of Chicago Law Review, University of Chicago Law School, Volumen 58, No 2, Primavera 1991, pp. 633-670.

10 Buchanan, Allen, "Theories...", p. 36. 
los mecanismos para decidir la secesión, pero no permite omitir la elección de los individuos que desean separarse.

Buchheit señala que para ejercitar un derecho a la secesión de último recurso se debe antes transitar por todo un proceso que permita mantener la integridad territorial del Estado por sobre el derecho a la autodeterminación de los individuos involucrados. Indica: "La secesión remedio visualiza un esquema por el cual, correspondiendo a los varios grados de opresión infligidos sobre un grupo particular por su Estado gobernante, el derecho internacional reconoce un continuum de remedios que van desde la protección de los derechos individuales, a los derechos de las minorias, y terminando con la secesión como el remedio último" "I. Sobre esta base, Buchheit efectúa un cálculo de la legitimidad de la secesión que resulta de la relación entre el nivel de opresión al que los individuos se encuentran sometidos y el grado de ruptura que se requiere en la sociedad para remediar tal tiranía, cuestión que, al menos, es dudosa en cuanto a su estimación.

Además, Buchanan no se conforma en caso alguno con las simples características particulares del grupo que desea separarse, ni tampoco le basta con cualquier índice de opresión para tener por justificada la secesión. Condiciona una secesión legítima para aquellos grupos que tradicionalmente aspiran a la secesión netamente por factores étnicos, lingüísticos o religiosos a los siguientes supuestos: la cultura debe estar efectivamente amenazada por la opresión; cualquier otra medida que en circunstancias normales podría preservar la cultura de una manera menos traumática que la secesión resultan, en el caso particular, estar no disponibles o ser inadecuadas; la cultura deberá cumplir con estándares mínimos de decencia moral; los secesionistas no deben desear el establecimiento de un Estado no liberal, que infrinja los derechos fundamentales de las personas y que impida la salida de aquellos que no quieren someterse a su jurisdicción; y por último, ni el Estado ni un tercero deben poseer una reclamación válida respecto del territorio que ocupan los secesionistas ${ }^{12}$.

Es en este punto donde la secesión remedio comienza a mutar hacia un enfoque territorialista. Así, Lea Brilmayer lidera una corriente de pensamiento muy provocativa que centra la cuestión de la secesión no en los individuos, sino que en el territorio que ocupan. Para ella, cualquier secesión constituirá un conflicto versando sobre reclamaciones territoriales. La soberanía legítima sobre el territorio será la que facultará a un conjunto de individuos para separarse o no del Estado en cuestión. Si existe un agravio territorial histórico, los secesionistas se verán justificados para separarse; en caso que sólo sea el Estado el que tenga un título jurídicamente legítimo sobre el territorio, los individuos podrán reclamar la protección de sus derechos dentro de éste, pero no

11 Buchuelt, Lee C., Secession. The Legitimag of Self-Determination, Yale Lnivensiry Press, Vew Haven, Estados Lnidos, 1978, p. 222.

12 Buculasin, Allen, Secession, p. 153. 
podrán exigir su salida de él ${ }^{13}$. Naturalmente, esta tesis merece diversas crícicas, pero éstas exceden el objeto de este trabajo.

\section{B. Teorias de La Secesión Derecho Primario}

Las teorias de esta especie, sean ellas adscriptivas o asociativas, comparten como elemento común, y contrario a las teorías de la secesión remedio, que existirá un derecho general a la secesión aun en ausencia de cualquier injusticia, motivo por el cual se asume que la secesión no tiene un efecto correctivo. A mi juicio, éstas son las teorías que más se condicen con los principios liberales, puesto que miran a las libertades de los individuos que pretenden separarse y no a los motivos que puedan tener éstos para hacerlo, aun cuando puedan representar cierto interés para su estudio. La noción de secesión que se maneja en esta aproximación hace referencia a las condiciones que los individuos deben satisfacer para ejercer este derecho.

\section{- Teorias Adscriptivas de La Secesión:}

Aquéllos que argumentan en este sentido incorporan al discurso secesionista cuestiones provenientes de los principios nacionalistas. Sin duda, y paradójicamente en su relación con un Estado liberal, éstas son las teorías más comunitarias de las antes señaladas, dado que prestan especial atención a las características del conjunto de individuos que busca separarse.

La secesión es para los teóricos de esta argumentación, una cuestión identitaria. Los individuos poseen características comunes, que los llevan a estar identificados con otros individuos, lo que a su vez les facultaría, según estas teorías, para determinar su destino del modo que les parezca. Conforme a éstas, toda identidad dará a pie a la formación de una cultura particular. En posesión de tal cultura, los individuos estarán facultados para ejercer un derecho a ésta, así como un derecho al autogobierno.

Las características adscriptivas existen, según Buchanan. "independientemente de cualquier asociación politica actual que los miembros del grupo puedan baber forjado" ${ }^{4}$. Son los rasgos comunitarios, de carácter no político, los que definen a los individuos, facultándoles para asociarse políticamente en función de ellos. La nueva asociación política encuentra su fundamento en la idea de que el mayor bienestar de tales individuos lo podrán alcanzar en un Estado diverso de aquél en que actualmente se encuentran insertos.

Avishai Margalit y Joseph Raz, teóricos de esta corriente, relacionan la idea de secesión a la existencia de determinados conjuntos de individuos que poseen tales características, los denominados "grupos encuadrantes" (encompassing groups). Para ellos "el derecho a

13 Bricmayrer, Lea, "Secession and Self-Detcrmination: A Tetritorial Interpreation", en Yale foumal of Internationat Law, Volumen 16, No 1, 1991, pp. 177-202, pp. $189 \mathrm{ss}$.

14 Buchasin, Allen, "Theories...", p. 38. 
la autodeterminación deriva del valor de las membresias en grupos encuadrantes. Es un derecho de grupo, derivando del valor de un bien colectivo, y como tal opuesto en espiritu a las aproximaciones contractuales-individualistas" ${ }^{15}$. Estos grupos encuadrantes se caracterizan y distinguen de otros grupos por poseer un carácter y cultura comunes, abarcando la mayor parte de los aspectos vitales; estar formados de una manera especial por tal carácter y cultura; su membresía está basada en el principio de aceptación mutua, lo que es de gran relevancia para la identidad individual; sus miembros son nacidos en la comunidad; y esta ưltima no es un grupo de reducido tamaño, una comunidad "cara a cara" 16 .

La noción de secesión que se maneja en esta teoría es particularmente exclusivista. No cualquier individuo está habilitado para autodeterminarse, o bien (respecto de este estudio) separarse, sino que sólo lo harán aquellos que pertenecen a tales grupos encuadrantes. Obtener la membresía en tal grupo es altamente difícil, casi imposible, pues el determinismo juega aquí un rol de primera importancia. Bien señalan: " $\mathrm{La}$ membresia es una materia de pertenencia, no de logro" ${ }^{17}$. La consecuencia lógica del razonamiento de estos autores viene a ser que sólo los grupos encuadrantes podrán separarse, fundados en sus propias características y sin injerencia del Estado gobernante, estableciendo así su propio estatuto, pudiendo regir a quienes aceptar o rechazar como miembros de su Estado, su propio y exclusivo club político. Esta tesis es sostenida también por el notable filósofo Michael Walzer, quien indica que "[s] i la comunidad (estatal) está tan radicalmente dividida que una ciudadania única es imposible, entonces el territorio debe ser dividido, también, antes que los derechos de admisión y exclusión puedan ser ejercidos. Estos derechos son para ser ejercidos sólo por la comunidad como un todo (incluso si, en la práctica, alguna mayoría nacional domina la toma de decisiones) y sólo respecto de extranjeros, no por algunos miembros con respecto a otros" 18 .

Las teorías adscriptivas son también denominadas de la autodeterminación nacional precisamente por su característica de teferirse sólo a grupos calificados para ejercer el derecho a la secesión, expresión de autodeterminación. En este contexto, como en ningún otro, los estudiosos de la autodeterminación, que agotan largas páginas en defrnir "pueblo" o "nación", encuentran terreno fértil para sembrar tales análisis. Estos grupos, poseedores de una cultura particular, !a cual genera un derecho tanto a clla misma como al autogobierno, serán los únicos sujetos del derecho a la secesión. Indica Buchanan que "[l] o que hace de un grupo una nación o un pueblo es el hecho de que tiene una cultura, historia, lengua, un sentido de su propio carácter distintivo comunes, y quizás una aspiración compartida para constituir su propia unidad política. Ni la organización

15 Makcaltr, Avishai y RAz, Joseph, “National Self - Dercrmination”, en The Journal of Philosophy, Volumen LXXXVII, No 9, Septiembre 1990. pp. 439-461, p. 456.

16 Ibidem, pp. 445-447.

Ibidem, p. 446.

18 WLZER Michacl, Spheres of fustice: A Defense of Phunalism and Equatity, Basic Books, Nucva York, Estados Linidos. 1983 , p. 62. 
politica actual del grupo; ni cualquier elección colectiva actual para formar una asociación politica, es necesaria para que el grupo sea una nación o un pueblo" 19 . Aun cuando la secesión no se funda en la decisión actual del grupo, sí requerirá de ella para ejercer el derecho, dado que, en la teoría de Margalit y Raz, la mayoría del grupo deberá expresar tal deseo por medio de una votación democrática ${ }^{20}$, siempre buscando resguardar la subsistencia de la cultura comunitaria, y ofreciendo garantías de protección de los derechos humanos y de los intereses de los terceros Estados ${ }^{21}$.

- Teorías Asociativas de la Secesion:

En esta aproximación, la secesión no responde a la existencia de un grupo definido por sus características en común y tampoco al sentimiento de pertenecer a uno siquiera supuesto. La secesión se funda en el deseo de los individuos de sujetarse a su propio $E_{\text {Estado }}^{22}$, es decir, en la propia decisión de un conjunto de individuos; en las palabras de Buchanan, estas teorías "se concentran en la elección política voluntaria de los miembros de un grupo (o La mayoria de ellos), su decisión para formar su propia unidad politica independiente ${ }^{23}$.

Este conjunto de individuos se encuentra inserto en un esquema voluntario: su pertenencia no está determinada más que por el deseo común de separarse, sin conexiones de naturaleza culcural alguna entre ellos, así como tampoco respecto de su territorio. Aun cuando en los hechos pueden tener en común rales aspectos, ello es irrelevante para estas teorías, puesto que sólo la decisión individual es la que ha de prevalecer para tener por justificada la secesión. La secesión tiene su fundamento no en agravios externos ni tampoco en caracteres culturales de índole interna, sino que en la libertad de asociación política, derecho individual y arraigado en los principios liberales de la comunidad internacional. Así, los secesionistas podrán, al igual que en las teorías adscriptivas, pretender la separación de un Estado completamente justo, ya que la secesión es un derecho ligado al fuero interno de los individuos y no a circunstancias externas, como serían los actos opresivos del ente gobernante ${ }^{24}$. Éstas son indudablemente las teorías quc mayor coherencia guardan respecto de cualquier Estado liberal, pero debido

19 Blchandi, Alicn, "Theories...", p. 38.

¿n En estc purto, la teoría ziende a fundirse con las de la elección. La difercncia, indudablemente, radica en quienes podrán votar: en las reorías de la autodeterminación, sólo lo harán los mierribres de cada grupo encuadrante: en las de la elección, serán todos aquéllos que pertenezcan a la comunidad policica que sc scpara, como veré al tratar las reorias asociativas.

I Marcialte, Avishai y Raz, Joseph, op. cit., pp, 459-460.

21 Ciertamente, por sujetarse a sk propio Estado hago referencia a la circunstancia de que tales individuos pueden no únicamente crear un Estado propio, sino también incorporarse a uno ya existente o asociarse a ocro definiendo su propio estacuto,

3 Buchanan, Allen, "Theories...", pp. 38-39. He de hacer la salvedad de que Buchanafs sólo hace mención de la secesión independentista, pero estas teorias son aplicables tambićn a toda secesión. incluso irredentista o asociariva.

$\therefore$ Ibidem, p. 40 . 
al grado de permisibilidad que atribuyen al derecho son aquéllas que aparentemente mayor rechazo generan en la opinión pública internacional.

Necesario es, dentro de estas teorias, distinguir algunas de sus variaciones. Uno de los principales autotes que sostienen esta posición es Harry Beran, quien basa la noción de secesión en su llamada "teoria del consentimiento de la obligación politica" ${ }^{25}$. Esta señala que la validez de un orden político, asi como los deberes que surgen de éste respecto de sus ciudadanos, no derivan de una relación contractual ni hipotética entre los individuos y el Estado, sino que se basan en un consentimiento actual por parte de los obligados. En este contexto, un Estado liberal (por tanto, respetuoso de todas las libertades individuales, incluso la de asociación política) sólo podrá asegurar la existencia de tal consentimiento, teniendo así por legítimas las obligaciones que impone a sus súbditos, si garantiza un derecho a la secesión a aquéllos que así lo deseen y decidan.

El Estado de Beran es coincidente, al menos en sus aspectos generates, con el ideal del liberalismo: la libertad como valor máximo y último, en todo ámbiro. Para Beran, el Estado es sólo un mecanismo que ha de permitir a los individuos ampliar su libertad, no restringirla ${ }^{26}$. El libre albedrío de todo individuo no debe, por tanto, sólo reservarse al ámbito doméstico, sino que ha de manifestarse incluso en sus relaciones con el Estado que le obliga. Así, dice que:

[e]n tales sociedades el cónyuge de uno es elegido por uno mismo, no por los padres de uno; uno elige o logra su status en el empleo, uno no ha nacido para él; y los gobiernos son elegidos en elecciones entre candidatos que se ofrecen a sí mismos para el servicio. Ni son tales relaciones, una vez asentadas, irrevocables. El divorcio está permitido, las relaciones laborales pueden ser terminadas, los gobiernos pueden ser votados fuera del servicio. Más aun, la relación entre el ciudadano adulto individual y el consistentemente Estado liberal es voluntaria, desde que tales ciudadanos tienen el derecho a emigrar y a cambiar su nacionalidad ${ }^{27}$.

En la teoría liberal de Beran, cualquier grupo concentrado territorialmente al interior de un Estado está facultado para la secesión, en caso que así lo decida y siempre que ello sea moral y prácticamente posible ${ }^{28}$. Hasra este punto, la teoría de Beran es en extremo respetuosa de las libertades individuales, limitando su campo de acción sólo a la concentración territorial de los individuos que desean separarse (lo cual ya es discutible desde la perspectiva de la teoría que apoyo). A pesar de ello, cede a la realidad, concre-

3 Beran. Hamp. The Consent Theory of Tolitical Obligation, Croom Helm International Series in Social and Political Thought, Crowm Helm Publishers L.cd., Londres, Reino Cinido, 1987 (respecio del rema que me oxupa, véase especialmente pp. 37-42).

26 En esta opinión, es indudable el influjo ejercido en Beran por el ya célebre pensamiento de John Rawls en corno a su concepción de una sociedad justa como un esquema voluntario. A respecto, Rawrs, John, A Theory of fustice, the Belkstap Press of Harvard University Press, Cambridge, Esrados Unidos, 1971, p. 13.

2 Beran, Harry, "A Liberal Theory of Secession", en Political Studies, Political Studics Association, Blackwell l’ublishing Limited, Volumen XXX11, No 1, Marzo 1984, pp. 21-31, pp. 24-25.

so Broun, Harry, The Consent..., p. 41. 
tando en diversos ejemplos situaciones moral o prácticamente imposibles de secesión, entre las que se cuentan que el grupo no sea lo suficientemente grande para formar un Estado (olvidando la existencia de secesiones irredentistas, que no exigirían tamaño; además, los micro-Estados no son cuestión desconocida en la praxis internacional); que no esté preparado para permitir separarse a subgrupos calificados para ello; que busque oprimir o explotar a un subgrupo no calificado para separarse; que ocupe un área no limítrofe, lo que originaría un enclave; que ocupe un área cultural, económica o militarmente esencial para el Estado; o que ocupe un área con una desproporcionada parte de los recursos del Estado 29 . Sin comentar tales ejemplos, y aun cuando Beran se hace cargo de atenuar tales situaciones en varios trabajos ${ }^{30}$, como respuesta a diversas críticas liberales ${ }^{31}$, esta enunciación es, a mi parecer, sólo reflejo de una interferencia de la teoría de la secesión remedio, ya que habrían casos en los cuales, pese a que los individuos tienen la libertad para asociarse, no podrán hacerlo por razones externas, asimilables a la ausencia de opresión.

Otro autor que asume una posición liberal respecto de la secesión es Christopher $\mathrm{H}$. Wellman. Él propone una teoría híbrida de la secesión concebida como un derecho primario de asociación política ${ }^{32}$. En ésta, evade los efectos perniciosos del modelo consensual de secesión propuesto por Beran (aquétlos que este último busca remediar con sus ejemplos), como también pretende otorgar más libertad a los individuos que la que entregan los modelos de la secesión remedio y el teleológico, variante ésta caracterizada por admitir la secesión en sólo aquellos casos en que el Estado gobernante no cumple con estándares de eficiencia, permitiendo así a los secesionistas desenvolverse con tales niveles de que carece el Estado ${ }^{33}$. Para Wellman, este derecho corresponde a cualquier grupo que resida en un territorio, siempre que cumpla con tres requisitos: constituir una mayoría en ese territorio (de allí la idea de elección de estas teorías); estar habilitado para desempeñar de manera efectiva las funciones estatales primordiales; $y$ no dejar al Estado gobernante en una situación que le impida ejercer su propio derecho a la autodeterminación política, vale decir no puede dejar a este ente muy desmejorado ${ }^{\text {jq }}$.

: Beran, Harry, "A Liberak...", pp. 30-31. Fstos cases son reiterados en Beran, Harry, The Conernt... p. 42.

vo Lo hace en el mismo "A Liberal...", p. 31. Con mayor detalle, hace sus descargos en Berax. Harry, "More Thency of Secession: A Response to Birch", en Political Stzdies, Political Studies Association, Blackwell Publishing I.imited, Volumen XXXVI, No 2, Junio 1988, pp. 316-323.

"i Ia más notable de ellas es probabiemente la de Anthony H. Birch, "Anorher Liberal "Thenry of Secession", en Political Studies, Political Studies Association, Blackwell Publishing Limited, Volumen XXXII. Na 4, dicicmbre 1984, pp. 596-602.

3. Wellman, Christopher H., "A Defense of Secession and Political Self - Derermination", en Philasophy of Public Affairs, ['tinceton University Prcss, Volumen 24, No 2, Primavera 1995, pp. 142-171, p. 142.

st. De más está señalar que esta aproximación, fuerremente economicista, limita el derecho a la secesión tanto como las reorias dé últimu recurso, dado que siempre existirá un factor externo, culpa del Escado gobernante, que facultará a los individuos para scpararse.

34 WLLMAN, Christopher H., up. cil., p'p. 161-164. 
Por último, una de las argumentaciones más extremas, pero la que también es, según mi parecer, aquélla que más se condice con todo Estado liberal protector de los derechos fundamentales, es la teoría puramente plebiscitaria, como la llama Buchanan ${ }^{35}$. En ésta, basta con que los individuos constituyan una mayoría en pro de la secesión dentro del Estado para tener un derecho a ella. Dentro de ésta, existen diversas variables, pero siempre existe el hilo común de una secesión regida por el liberalismo más amplio. Las divergencias surgen precisamente respecto de los límites de la secesión plebiscitaria. Un autor clásico sobre este punto es el alemán Ludwig von Mises, quien argumenta a favor de una secesión basada estrictamente en la decisión individual de la siguiente forma:

El derecho de autodeterminación, con respecto al problema de pertenencia a determinado Estado, para el liberal supone que todo territorio, sea simple aldea, provincia o conjunto de provincias cuyos habitantes libremente, en honesto plebiscito, se pronuncien por separarse de aquel Estado del que, a la sazón, forman parte, bien sea para crear una entidad independiente o para unirse a otra nación, pueda libremente hacerlo. He aquí la única via que efectivamente evita revoluciones, pugnas intestinas y guerras $^{36}$.

Con Mises, la noción de secesión pasa a fundarse más que nunca en la simple decisión individual, plasmada en un plebiscito o votación ad hoc. Agrega: “... no se trata de que cierta región, como tal entidad colectiva, se pronuncie, sino que son sus habitantes individualmente quienes han de decidir si, de verdad, desean o no inscribirse en este o aquel otro


de similitudes étnicas, pese a la voluntad de los interesados en contrario. Alega que el derecho a la autodeterminación no puede ser supeditado a ciertos intereses superiores de la nación, dado que lo único relevante aquí es la decisión de los individuos, aunque ésta sólo radique en los gustos personales ${ }^{38}$.

Finalmente, Mises se refiere precisamente a los límites de su secesión plebiscitaria:

Como es evidente, el derecho de autodeterminación al que el liberal alude nada tiene que ver con ese supuesto 'derecho de autodeterminación de las naciones', porque el liberalismo lo que defiende es la autodeterminación de los individuales habitantes de toda zona geográfica suficientemente amplia para formar su propia entidad administrativa. Y esto hasta el punto de que, si fuera posible conceder el derecho de autodeterminación a cada individuo, el liberal entiende también habría de serle otorgado. No es posible, desde luego, en la prácrica, estructurar tal planteamiento, por razones puramente técnicas, en razón a que la zona de que se trate por fuerza ha

"Buchanan, Allen, "Theories...", p. 39.

56 Mises, Ludwig von, Liberalisme, Traducción de Joaquin Reig Albiol, Segunda Fdición, Editorial Universidad Francisco Marroquín, Ciudad de Guaremala, Guatemala, 1982, p. 139.

$3 \quad$ Ibidem, p. 139.

s\% Ibílem, p. 141. 
de tener bastante entidad como para ser posible administrativamente gobernarla. La autodeterminación, por eso, no puede ir más allá de los habitantes de aquellas unidades territoriales que tengan ciesto peso demográfico ${ }^{39}$.

De esta manera, la secesión de Mises llega al borde de la anarquia, puesto que sólo obstan para el reconocimiento de una secesión individual motivaciones de carácter práctico. Éstas son incluso removidas por Murray Rorhbard:

... ireconocería un promotor del laissez-faire el derecho de una región de un país a separarse de ese país? ¿Es legítimo para Ruricania Occidental separarse de Ruritania? Si no, ¿̨por qué no? Y si es así, entonces ¿̨cómo puede haber un punto de detención lógico para la secesión? ¿ No puede un pequeño distriro separarse, y luego una ciudad, $y$ luego un suburbio de esa ciudad, y luego un bloque, y luego finalmente un individuo particular? Una vez se admita cualquier derecho de secesión, y no haya punto de detención lógico cerca del derecho a la secesión individual, el cual lógicamente supone el anarquismo, desde entonces los individuos podrán separarse y patrocinar sus propias agencias de defensa, y el Estado se ha desmoronado ${ }^{40}$.

Robert McGee, uno de los principales teóricos contemporáneos de esta posición, señala: "¿Cuándo está justificada la secesión? En una palabra: siempre. No bay una razón legitima para prevenir a la gente de tener el gobierno de su elección, incluso si su elección es una pobre. El gobierno es legitimo sólo basta el grado en que existe por el consentimiento de los gobernados. Argumentar en contra de la secesión es argumentar contra el derecho de los individuos a tener el gobierno de su elección" "1. McGee sostiene una tesis con menor número de limitaciones que la de Mises, pero sin llegar al extremo anárquico planteado por Rothbard. Indica que el tamaño no determinará la posibilidad de la secesión, sino que sólo la fórmula secesionista a aplicar. Así, en algunas situaciones de conjuntos de individuos demasiado pequeños sólo será recomendable una secesión local, sin traspasar las fronteras estatales. Cuando se llega al extremo de una secesión individual, éste propone una especie de irredentismo interno, permitiendo a cada persona cambiar de jurisdicción, pero no aspirar a la independencia ${ }^{12}$. Además, puesto que no todo Estado busca desempeñar las mismas funciones y sus súbditos tampoco les exigen las mismas, la dimensión física del Estado tampoco requerirá ser siempre la misma ${ }^{45}$. Una síntesis del pensamiento liberal de McGee se presenta en la siguiente frase: "La secesión es un derecho, no algo para lo que debas tener permiso"

39 Ibidem, p. 140.

1) Rothrapo, Murray N., The Ethics of Liberty, New York Liniversiry Press, Now York Liniversity, Nueva York, Esrados Ĺnidos, 1998, p. 182. Sobre la secesión individual, yéase ambién Brichanar, Ailen, Secession, pp. 1314.

"MCGEE, Robert W., "Secession Reconsidered", en Journal of Libertarian Studies, Cencer for I. ibertarian Studies, Volumen I1, パ 1, Otoño 1994, pp. II-33, p. 21. El énfacis es propio.

+2 McGeE, Robert W., "A Third Liberal Theory of Secession", en The Liverpoot Law Review, Volumen 14. No I, 1992, pp. 45-66, pp. 51-53.

4. MoGEE, Robers W., "Secession...", p. 28.

14 MCGeE, Robert W., "A Third...", p. 59. 


\section{La Secesión de Montenegro como Caso de Estudio}

El 21 de mayo de 2006 los habitantes del Estado federado de Montenegro se pronunciaron en un referéndum a favor de la secesión respecto de la unión que formaban con la República de Serbia. La Unión Europea, en calidad de observadora del proceso secesionista, acordó con el gobierno montenegrino que el reconocimiento de la Unión seria otorgado si se obtenía al menos una mayoría del $55 \%$ de los votos favorables a la separación, en orden a asegurar la legitimidad del referéndum y de una posterior independencia ${ }^{45}$, porcentaje que se alcanzó estrechamente con un $55,5 \%$. Esta situación, que dio origen al primer nuevo Estado europeo del siglo XXI, es un excelente ejemplo de la aplicación de las teorias de la secesión en la práctica internacional. No obstante ello, ¿cuál es la posición dominante en la separación montenegtina? Un análisis de los diversos aspectos de esta secesión arrojará conclusiones muy interesantes.

La primera cuestión en la que se debe reparar para analizar la secesión de Montenegro es su carácter plebiscitario. Todo el proceso secesionista montenegrino se fundó únicamente en la decisión libre de sus habitantes, sin hacer referencia a agravios precisos inferidos por Serbia, predominante en el gobierno central de la República de Serbia y Montenegro, ni tampoco haciendo mención directa a alguna identidad nacional específica del conjunto de los habitantes de Montenegro ${ }^{46}$. Naturalmente existió en la opinión pública de los secesionistas un cierto sentimiento referido a una supuesta explotación económica, a una postergación política y a ciertos agravios morales sufridos durante el régimen de Stobodan Milosevic, pero ninguno de estos argumentos significó el núcleo del discurso separatista. Éste sólo se basó en la decisión de los montenegrinos en orden a separarse de Serbia, particularmente porque su voluntad era tal, sin requerir de algún apellido político, como consta en la prensa internacional ${ }^{4{ }^{*}}$.

a) La proposición relativa a este porcentaje fue hecha por Bruselas dado el fracaso de las negociaciones entre serbios y monrenegrinos sobre este punto. Para un comentario acerca de la elección de esta cifra, que parece ser bastance arbitraria cn su aplicación al caso montenegrino, véase el muy recicnte trabajo de ScHmícker, Reinold. "Cerechrigkcit und Tenitorialität", en Deutsche Zeitschriff für Phibsophie, Berlín, Alemania, Volutten 54, No 4, 2006, pp. 597.621, p. 608. Tras haber pactado ral porcentaje, el Primer Ministro de Montenegro. Milo Đukanovi, declaró que seguiría adelante con el proceso sccesionista aun si la votación favorable a la separación superaba el $50 \%$, pero no alcanzaba el $55 \%$, lo cual de haber acaecido sin duda hubiese generado una crisis politica en una región que ha estado usualmente afectada por esta clase de convulsioncs. Véasc 'I'esLIx, lec Hudson, "Montenegro"s Referendum on Independence", en Council on Forrign Relations, 19 de Mayo de 2006, disponible en hatp://wuru. fr.pry/publication/10725/montenegros_referendum on independence.bim/ (consulada cl día 23 de mayo de 2006).

7h Más aún, la posición coneraria a la itudependencia de Montenegro entre los serbios se fundaba en la ausencia del carácter "enchadrante" de la población montenegrina, dado que śsta no se diferenciaria écnicamente de los serbios, al menos sustancialmente hablando. No obstante esto, ni la op̣inión pública de Montenegro ni la internacional, parcicularmente la de obseryadores cono la Linión Europea y la Organización para la Seguridad y Cooperación en Europa (OSCE), pareció versc modificada por esca apreciación. Al respecto, en prensa " $Q$ \& A: Montenegro Reterendum", en $B B C$. News, 22 de mayo de 2006, disponible en hitp:/hnews, bbc.co.tkifolpr/fr/-/2/hi/europe/4994212.sm (consuleada el dia 24 de mayo dc 2006).

1- Rot ejemplo, véase arículo de prensa "Montenegro votes in independence Referendurn", cn International He rald Tribune, The Associated Press, 21 de Mayo de 2006, disponible en hrtp://wuwwiht.com/bin/print ipub. phpifile=/articles/2006/05/21/neus/useb.0521 serbia.php (consultada el día 23 de mayo de 2006). 
Llama la atención en este proceso que los secesionistas no son ciertamente cualquier conjunto de individuos, sino que constituyen un grupo de personas concentradas territorialmente al interior de una unidad política de carácter interno, la República federada de Montenegro. Ésta poseía límites definidos, incluso con anterioridad a la unión inicial con Serbia, en 1919, fecha en que Montenegro renunció a su subjetividad internacional. De todo ello es posible sostener algunas opiniones primarias. Al menos en sus aspectos generales parece ser que la secesión de Montenegro se rígió por los principios de las reorías asociativas del derecho a la secesión, con particular atención respecto de la tesis sostenida por Beran en cuanto se trataría de una secesión de grupos territorialmente concentrados, por lo cual los individuos no se bastan a sí mismos para la separación, sino que requieren de un territorio en el cual se encuentren reunidos. Lo que sí es excluido de esta teoría, así como también lo es aparentemente de la secesión montenegrina, son las características particulares de los secesionistas. No se necesitó para la secesión de Montenegro más calificación que la de habitante de este territorio para poder decidir acerca de su destino como Estado distinto del de Serbia. Los montenegrinos residentes fuera del país (entendiendo por montenegrino todo aquél nacido en territorio de Montenegro o de padres nacidos en tal lugar, sin referencia alguna a su etnia) podían también votar en el referéndum, salvo aquéllos que habitaban en Serbia, motivo por el cual parece ser se presumía su renuncia a los derechos otorgados por la autoridad de Montenegro ${ }^{48}$.

Por tanto, la membresía en la asociación estatal conformada por Montenegro no posee carácter exclusivista, como en las teorías adscriptivas del derecho primario a la secesión. Todo individuo con la voluntad de asociarse con otros en igualdad de condiciones tiene el derecho a la secesión, en orden a formar una nueva sociedad política, sin distinción alguna en cuanto a etnia, lengua o religión. I a nacionalidad montenegrina está definida por el ánimo de asociación política entre los individuos (una especie de affectio societatis, si se lo quiere llamar de algún modo) y no por la nacionalidad en sentido sociológico, como pertenencia a una determinada nación. Según el principio que se desprende del otorgamiento de la nacionalidad en el Estado recién formado, que se puede inferir de las particularidades de los votantes en el referéndum de secesión, nadie puede obligar a un conjunto de individuos a asociarse políticamente con otros bajo el supuesto de su pertenencia nacional, determinada ésta también por orros. Asimismo, nadie puede autodefinir tal pertenencia y pretender que sólo por ello sea aceptado en la nueva unidad politica. El principio de la nacionatidad en las teorías asociativas se rige por un criterio básico de reciprocidad, el cual tiene su fundamento en la misma libertad de asociación.

Un buen ejemplo de esta situación en el caso de Montenegro se encuentra en el análisis demográfico de la población de esta República. En conformidad a un censo llevado a

4* "Q \& A: Mantenegro Referendum". en BBC News, 22 de mayo de 2006, disponible en hmp:/news.b6c.co.ukt goipr/ffi-12/hileurope/49942/2.stm (consulada el dia 24 de mayo de 2006). 
cabo el año 2003, la población de esta zona asciende a 670.000 habitantes, los cuales hoy son ciudadanos del Estado montenegrino. De ellos, sólo un $43 \%$ son étnicamente montenegrinos ${ }^{49}, 32 \%$ serbios (concentrados en el norte), $14 \%$ eslavos musulmanes o boshnios $^{50}$ (concentrados en el exte), y $7 \%$ albaneses (en el sur) ${ }^{51}$. Por esta composición mixta de la población es que se hacía necesario un proyecto de Estado montenegrino distinto de aquéllos de las Repúblicas surgidas tras la disolución de la ex Yugoslavia. Así, las mismas autoridades promovieron la independencia de "Montenegro como sociedad multiétnica, multiconfesional y multicultural" ${ }^{2}$, to qute derivó en el fomento de un nacionalismo cívico, distinto del modelo propuesto anteriormente en los Balcanes, incluso hasta llegar a Kosovo. Este nacionalismo cívico se condice de mejor manera, a mi juicio, con el ideal de Estado liberal, ya que tiende a un proyecto de sociedad política inclusiva e igualitaria.

Como consecuencia de lo expuesto, no se propone un Estado para la comunidad étnica montenegrina, sino que un Estado para toda una sociedad política integrada por diferentes grupos étnicos. Bien señalan Dérens y Geslin:

Por primera vez en la historia teciente de la región [los Balcanes], las minorías nacionales de un país se unieron a la comunidad principal en torno a un proyecto político. La independencia croata se basó en la exclusión de los serbios del país; los albaneses de Macedonia nunca adhirieron al proyecto de Estado macedonio, y en Kosovo sólo los albaneses desean la independencia. Los independentistas de Montenegro defendían un proyecto de Estado multiétnico y ćvico, inviable sin la adhesión de todas las comunidades $^{53}$.

De lo anterior, pese a no ser aún siquiera discutida en la reciente secesión montenegrina, es posible concebir la existencia futura de secesiones recursivas en Montenegro, debido a la presencia de grupos de individuos que podrían en determinadas circunstancias

49 Ya he señalado que la oposición serbia ha sostenido que no existc difercncia ćtnica sustancial entre montenegrinos y scrbios, por lo cual estiman la secesión no es legírima en sus fundamentus. En este sencido, si se tiene por vỉlida tal afirtnación, los serbios estarín sustentando una tesis adsctiptiva del derecho a la scccsión. Al confrontat ésta a la teoría asociativa monrenegrina, queda metidianamente claro que no exisría solución lógica para este conflicto si cada cual permanecia fuertertiente sujeto a 5 u propia tesis $s_{+}$por lo que se hacía necesario renunciar a una cn bencticio de la posición contraria. Asi, ras el éxito de la scccsión montenegrina es posible sostener que la tesis ascxiativa es la que más pesó, lo que a su vez permite persiar que tanco el Estado serbio como el montenegrino intentan asumir una vocación liberal a semejanza de sus vecinos europeos.

50 Por boshnio (bosnjaci) ha de cntenderse a aquel individuo miembro de la comunidad musulmana reconocida corno nacionalidad separada bajo la Yugoslavia socialista, término diverso (aunque pudiendo ser coincidentc) del de brosnio (bosanci), utilizado para definir a aquel ciudadano de Bosnia-Herzegovina. Véase DÉrens, JFAN - Arnault y Gesinn, Laurent, "Los Desafios de Serbia", en Le Monde Diplomatique (Edición Chilenat, Edìtorial Aún Creemos en los Sueños, Año VI, No 65, julio 2006, pp. 16-18, p. 18.

51 "Q \& A: Montenegro Referendum", en BBC News, 22 de mayo de 2006, disponible en hitp:/newes. becico.ukt go/pr/ff/-2/hi/europel4924212.stm (consultada el dia 24 de mayo de 2006).

52 Declatación del Gobierno de la República de Montenegro dirigida a los Ciudadanos de Montenegro, de 6 de

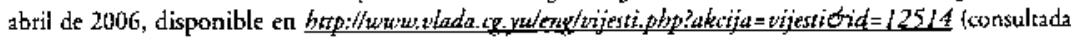
el día 30 de junio de 2006).

3.5 Derens, JeAN - ARnault' y Gislin, Laurent, op. cit., p. 16. 
políticas e históricas constituirse en "minorias atrapadas", viendo en dicha situación vulnerados sus derechos fundamentales, especialmente el de autodeterminación ${ }^{54}$. Es más, en el largo plazo la misma secesión de Montenegro podría ser considerada recursiva respecto del remanente de la ex Federación de Yugoslavia, si es que Serbia y Montenegro pudiese ser tenido también como Estado secesionista surgido tras la disolución del Estado federal ${ }^{55}$. El carácter recursivo ${ }^{56}$ de una secesión está determinado por el nivel en el que se presenta dentro de un macroproceso secesionista: ésta será la secesión dentro de la secesión, aquélla detonada por una secesión previa de un Estado ya reconocido y afianzado. Nada en el liberalismo permite suponer que la secesión propiamente tal deba también ser la última.

Los efectos de la secesión recursiva no se relacionan únicamente con el capricho de un conjunto de individuos en orden a separarse de un Estado nacido de otra secesión,

54 Esta terminología es adoptada especialmente por Buchheit, subrayando que la existencia de estos grupos obsta a un derecho general a la secesión, lo cual creo no es efectivo, ya que nada impide que ellos, como en el caso montenegrino, puedan favorecer la separación. Además, incluso en contra, siempre podrán hacer uso de su derecho recursivo a la secesión, el cual les debe ser admitido en todo Estado que pretenda respetar las libertades individuales. BuchHert, Lee C., op. cit., pp. 29-30. Además, sobre las "minorias atrapadas" y su situación en el periodo posterior a la secesión, no precisamente coincidente con mi opinión, véase MCGARRY, John, "Orphans of Secession': National Pluralism in Secessionist Regions and Post - Secession States", en Moore, Margaret (editora), National Self-Determination and Secession, Primera Edición, Oxford University Press, Oxford, Reino Unido, 1998, pp. 215-232.

55 Así, la prensa ha llamado a la secesión de Montenegro como el "último divorcio" ocurrido entre las originales seis Repúblicas yugoslavas, que además de Serbia y Montenegro, incluían a Croacia, Eslovenia, Bosnia-Herzegovina y Macedonia, sin contar a las provincias autónomas serbias de Kosovo y Vojvodina. Véase BiLandzic, Beti, "Montenegrin Leader claims Independence Victory", en Reuters, 21 de mayo de 2006, disponible en http://today. reuters.com/misc/PrinterFriendlyPopup.aspx?type=worldNeusérstoryID2006 (consultada el día 23 de mayo de 2006). Además, dice Bieber que "Tl]a reivindicación independentista de Montenegro puede ser considerada como el último dominó de una larga serie de exigencias de autodeterminación emitidas en el seno de la Federación yugoslava a partir de 1991". BIEBER, Florian, "Monténégro: Le Chemin de l'Indépendance", en La Documentation Française, disponible en bitp://www ladocumentationfrancaise.fr/dossiers/serbie-montenegro/independance-montenegro.html (consultada el día 5 de junio de 2006). No obstante, cabe recordar que la Unión estatal de Serbia y Montenegro, continuadora legal de la nueva República Federativa de Yugoslavia existente hasta 2003, no fue de modo alguno sucesora de la Federación yugoslava existente con anterioridad a 1991. Ésta fue disuelta con tal fecha y ninguno de los nuevos Estados surgidos tras su término asumió su continuidad internacional, por lo que tanto la nueva República como los demás cinco Estados surgidos tras la disolución quedaron en igualdad de condiciones desde el punto de vista internacional. Incluso la nueva República de Yugoslavia debió solicitar su admisión en Naciones Unidas como nuevo Estado, sin poder ocupar el puesto dejado libre por la Federación extinta. En esta materia, véase Buum, Yehuda Z., "UN Membership of the 'New' Yugoslavia: Continuity or Break?", en The American Journal of International Law, American Society of International Law, Volumen 86, No 4, Octubre 1992, pp. 830-833; y VILLANI, Ugo, "Lo Status della Repubblica Serbo - Montenegrina nelle Nazioni Unite”, en Rivista di Diritto Internazionale, Giuffrè Editore, Milán, Italia, Volumen LXXVI, Fascículo 1, 1993, pp. 26-36.

56 El término recursivo para definir una secesión lo he tomado del trabajo de Aleksandar Pavković, quien lo utiliza precisamente en este contexto. Véase Pavković, Aleksandar, "Recursive Secessions in Former Yugoslavia: Too Hard a Case for Theories of Secession?", en Political Studies, Political Studies Association, Blackwell Publishing Limited, Volumen 48, No 3, junio 2000, pp. 485-502; PAVković, Aleksandar, "Secession as Defence of a Political Liberty: A Liberal Answer to a Nationalist Demand", en Canadian Journal of Political Science/ Rerue Canadienne de Science Politique, Canadian Political Science Association, Volumen 37, No 3, Septiembre 2004, pp. 695-713; y Pavković, Aleksandar, "Secession, Majority Rule and Equal Rights: A Few Questions", en Macquarie Law Journal, Volumen 3, 2003, pp. 73-94. 
subrayando lo caótica que podría ser la teoría. Por el contrario, la secesión recursiva sería la única maneta efectiva de asegurar los principios liberales en un nuevo Estado, ya que de otra forma los subgrupos minoritarios "atrapados" al interior de este último verían truncado su derecho a determinar su destino político. Señala acertadamente Pavković que la aplicación recursiva del principio mayoritario produce secesiones recursivas (o secesiones dentro de secesiones) las cuales a su vez excluyen el uso det mismo principio mayoritario para imponer un Estado sobre minorías indispuestas territorialmente concentradas. El ejercicio de este derecho se propone 'maximizar el número de individuos que viven en asociaciones políticas mutuamente deseadas', $y$ se dirige a establecer fronteras políticas justas, eso es, fronteras determinadas por el principio mayoritario democrático ${ }^{57}$.

Tal como Pavković, Harry Beran cree en un derecho a la secesión política, pero de sustrato territorial, esto es, de individuos asentados en un territorio determinado. En virtud del principio mayoritario, las secesiones recursivas deben producirse necesariamente en Estados liberales democráticos, cuyos subgrupos hayan decidido separarse. Nada obsta a que, por tratarse de un Escado surgido de una secesión, se deba prohibir a sus individuos separarse; su Estado es, para estos efectos, como cualquier otro, en el cual podrá ser ejercido el derecho a la secesión cuantas veces se decida ${ }^{38}$.

El problema de la secesión recursiva, siguiendo a Beran, se concentraría en la diversidad dentro de un mismo territorio, el cual no podría ser identificado con el principio mayoritario. Para este autor, cualquier grupo territorialmente concentrado será candidato potencial para una secesión que le será permitida por el Derecho ${ }^{59}$, por lo que no hace distinción entre estos grupos en Estados secesionistas o no. Esta llamada "comunidad territorial" es para Harry Beran "un grupo social que tiene un hábitat común, consiste de numerosas familias [...], y es capaz de autoperpetuacion a través del tiempo como una entidad distinta" ${ }^{\prime \prime}$. Una comunidad territorial candidata a una secesión ha formado, a su juicio, una mayoría en tal territorio, el cual es relevante por cuanto permite a los individuos conservarse a sí mismos ${ }^{61}$. Pero ¿y qué sucede si existen en partes de ese

s: Pavkovic, Aleksandar, "Secession, Majority Rule...", p. 78.

5a Algunos aurores, como Murray Rothbard, sostienen la recursividad hasra llegar a la scccsión indjuidual, lo cual implica renunciar at Hstado como organización polírica fundamenrał y promover una insticucionalidad anárquica, si se la puede li lamar de algún modo. Véase supra nota 40 . Mi posición difiere de ésta, por cuanto creo que el limite de la divisibilidad secesionista debe estar dado por su misma naturaleza asociativista: si la secesión es una libercad de asociación politica, dirigida a la creación de una nueva sociedad politica, los individuos deberán desasociarse para luego reasociarse, formando una nueva sociedad política. Conno es lógico, ninguna sociedad podrá estar consrizuida por un solo individuo, ni tampoco por un par a un trís, morivo por el cual se requiere una comunidad to suficientemente grande para autodefinise como sociedad y dejar de ser una familia. corporación o vecindario.

59 Beran, Hary, "A liberal Theary...", p. 29.

(4) Beran, Harry, "A Democratic Theory of Poliecical Self-Determination for a Ncw World Order", en Lelfning, Percy Blanchemains (editor), Theories of Secession. European Political Science Series, European Consortiun for Political Researth, Primera Edición, Routledge, Londres, Reino Unido, 1998, pp. 32-59. p. 36.

61 Ibidcrn, p. 36. Para Beran, el territorio es el único mecanismo de que disponen los individuos para manternerse integros, pero ellu the parece tener asidero jurídico, dado que cada individuo, aun careciendo de activos reales. es 
territorio otras comunidades de base territorial, que cumplen los mismos requisitos y forman mayorías en sus propias áreas, como es el caso de los serbios o los albaneses en Montenegro? Beran dice que el rechazo a su aplicación dentro de las filas secesionistas es un resultado incompatible con la teoría liberal, puesto que se permitiría recurrit al principio mayoritario en ciertos casos, mas no en otros igualmente calificados ${ }^{62}$. Por ello es que no queda más que aceptar la recursividad de la secesión en estas siruaciones, en conformidad al principio mayoritario con sustrato territorial. Es verdad que la decisión mayoritaria del grupo territorial más pequeño rechaza la decisión mayoritaria de aquél más grande cuyo territorio ha incorporado o pretende integrar el de la minoría ${ }^{63}$, pero el principio mayoritario requiere también que ambas partes, grandes y pequeñas, estén habilitadas para entrar en el juego político, pudiendo la una y la otra llegar al poder. Así, una comunidad territorial, por estar relativamente sujeta a su territorio, pocas y nulas posibilidades tendrá de ingresar en esta dinámica, por lo que sólo se visualiza como opción, en conformidad al principio comentado, a la secesión recursiva. Además, el gran temor que suscita esta forma de secesión es precisamente la infinita divisibilidad o "teoria dominó de la secesion", pero la evidencia práctica demuestra que escasamente las secesiones conducen a nuevas separaciones, particularmente tratándose de aquéllas pacíficas, como es el ejemplo de Montenegro, tal como subraya Beran ${ }^{64}$.

Pavković critica a Beran que, a pesar de admitir que la secesión recursiva parece ser el único mecanismo para resguardar de modo satisfactorio los derechos y la aplicación efectiva del principio mayoritario respecto de los grupos minoritarios al interior de un nuevo Estado, al restringir la teoría únicamente a las comunidades territoriales no hace más que establecer un sistema de derechos políticos desiguales en conformidad al status económico de los que desean separarse, sometiendo a aquéllos que carecen de territorio a una simple adhesión al modelo de toma de decisiones implementado por la mayoría. Por el contrario, los que poseen un "hábitat común" podrán separarse cuando

inviolable por su mistra dignidad, inherente a toda persona humana. Como sea, debe admitirse que los grupos sin territorio podrán ser, en la praxis, más susceptibies de ataques externos.

62 Bęan, Harry, "A Liberal "Theory...", p. 29. La circunstancia de que estas comunidades territoriales coincidan con grupos érnicos dererminados nó implica una renuncia a la ceoria asociativa del áesecho primario a la scecsión. Escos grupos éenicos, de seguir como principio el de la libertad de asociación sin consideración a las características particulares de los individuos que se asocian, seguirán aplicando las teorias de la libre elección. Por el contrario, si el factor étnico deja de ser una simple coincidencia y pasa a constiruirse en un dececho comunitario de carácter exclusiło y excluyente, la teeria podría derivar etr una de carácter adscriptivo, chesción que no me parect recomendable, icniendo en mente que cl cjeccicio de una libertad podria terminar justificando la suptesión de una igualdad, situación que no se presenta en las teorías asociativas, cuya incerprecación concilia de gran manera ambas clases de derechos.

47. Pavkovic, Aleksandar, "Sccession as Defence...", p. 698.

34 Beran, Harry, "A l.iberal Theory..." p. p. 29. Una sociedad polírica escatal fundada en el consentimiento actual de rodos o gran parte de sus individuos, sin mirar a su origen nacional, como parecte ser el caso de Montenegro, no es precisamente candidata a secesiones subsiguientes, puesto que sus miembros desean efectivancnte la pertenencia en ella. Asi, un proceso secesionista pacífico caramente derivará en secesiones recursivas. al mentess en el corto y mediano plazo. Naruralmente, las circunstancias pueden variar en un fururo, pero el temor de los ancisecesionistas pasa especialmente por generar una ola de secesiones conrinuas, las que no parecen lógicas cuando los individuos no han sido incorporados forzadamente en un nuevo Estado. 
lo decidan, sin limitación alguna, siquiera en principio ${ }^{65}$. Éste es el fundamento por el cual la secesión recursiva, pese a ser indudablemente acogida por mis planteamientos, no puede tener necesariamente base territorial, dado que debe estar abierto su ejercicio a cualquier individuo, posea o no un hábitat común, razón por la cual, en el ejemplo montenegrino, debiese ser aceptada respecto de cualquier subgrupo, incluso de aquéllos no concentrados territorialmente, como son especialmente los musulmanes.

Hasta este punto, la secesión de Montenegro parece ser manifestación de las teorías asociativas de este derecho. Pero ¿̇ebe esta afirmación ser tan rotunda? A pesar de creer que esta secesión sigue siendo expresión de una teoría de la libre elección, no es menos cierto que el ejemplo estudiado merece un par de aclaraciones. La secesión de Montenegro no se produjo únicamente por la decisión de sus habitantes en orden a separarse de Serbia expresada en un referéndum, sino que poseía un acuerdo explícito previo entre ambas unidades políticas. La unión estatal de Serbia y Montenegro fue establecida en marzo de 2002, por medio del Acuerdo de Belgrado, que reformuló las relaciones entre ambas Repúblicas y reemplazó a la anterior República Federativa de Yugoslavia nacida de la conjunción entre Serbia y Montenegro, surgida a su vez tras la disolución de la primera Federación yugoslava. Este acuerdo dio origen a la Carta Constitucional de la Unión de Serbia y Montenegro, de 4 de febrero de 2003, la cual, en su artículo 60, establecía el derecho a la secesión o al cambio de status de cualquiera de las Repúblicas miembros de la Unión. En tal disposición, se establecía que el procedimiento de secesión se realizaría por medio de un referéndum transcurrido el plazo de tres años contados desde la fecha de la Carta. Este referéndum debía considerar los estándares democráticos internacionales, en orden a obtener el reconocimiento de la comunidad internacional. Además, se indicaba que el Estado secesionista no sería en caso alguno sucesor ${ }^{66}$ de la Unión, puesto que la personalidad jurídica de ésta continuaría en manos del Estado remanente al término de la separación ${ }^{67}$. De esta manera, el proceso de secesión de Montenegro se desarrolló en conformidad a la normativa establecida en esta disposición, razón por la cual, una vez consumada la separación apenas transcurridos los tres años reglamentarios, Serbia se constituyó como continuadora ${ }^{68}$ internacional en la subjetividad de la Unión, permaneciendo con el asiento de ésta en Naciones Unidas y otras organizaciones internacionales, así como conservando los edificios de instituciones comunes del Estado, misiones diplomáticas

65 Pavković, Aleksandar, "Secession, Majority Rule...", p. 79.

66 Nótese la utilización del término "sucesor" para expresar la situación jurídica del Estado remanente post-secesión, siendo que éste permanecería verdaderamente y stricto sensu en una solución de continuación respecto de la Unión serbio-montenegrina, dado que ésta no sería disuelta (como en efecto sucedió en la especie, ya que la Unión siguió siendo identificada con Serbia); en caso contrario, sí habría sucesión, mas no continuación.

67 Para un buen comentario acerca de esta cláusula de secesión, véase JaKaB, András, "Die Verfassungscharta von 'Serbien und Montenegro', en Zeitschrift fiur ausländisches öffentliches Recht und Völkerrecht, Heidelberg Journal of International Law, Max-Planck - Institut für ausländisches öffentliches Recht und Völkerrecht, Volumen 63, 2003, pp. 801-815, pp. 810 ss.

68 "Sucesora", en los términos de la Carta Constitucional. 
y propiedad del Ejército ${ }^{69}$. Como consecuencia lógica, Montenegro debió solicitar su reconocimiento internacional en el seno de Naciones Unidas, más allá de aquél otorgado por Serbia, la Unión Europea, Estados Unidos y Rusia ${ }^{70}$. La admisión de la nueva República en Naciones Unidas fue aprobada por la Resolución 60/264 de la Asamblea General, de 28 de junio de $2006^{71}$.

La constitucionalización del derecho a la secesión es una cuestión inusual, mas no desconocida en el orden internacional ${ }^{72}$. Actualmente, estas cláusulas se encuentran presentes en los textos constitucionales de Etiopía ${ }^{73}$ y San Cristóbal y Nevis, por lo cual este mecanismo es visualizado como una forma de regular pacíficamente eventuales procesos secesionistas, los que normalmente son caracterizados por su violencia. En este contexto, la separación de Montenegro parecería ser expresión de un derecho especial a la secesión, de aquéllos formulados por Buchanan en su teoría de la secesión remedio, los cuales como ya he indicado, no exigen agravio alguno para legitimarla, a diferencia del derecho remedio de carácter excepcional de estas teorías.

No obstante, estimo que éste no es un caso de derecho especial a la secesión, fundado en su consagración constitucional. El espíritu de estas cláusulas es el de regular jurídicamente (y por tanto, proscribiendo cualquier acto de violencia) los procesos secesionistas eventuales, por lo cual el mecanismo no puede ser implementado dentro de estas teorías de manera de impedir el ejercicio inminente del derecho fuera del marco normativo constitucional. Así las cosas, la Carta Constitucional de Serbia y Montenegro consagró este derecho estableciendo un plazo de tres años únicamente para calmar los ánimos independentistas montenegrinos, existentes desde tiempo antes de la implementación de este texto ${ }^{74}$. Todo en Montenegro hacía presagiar esta separación ${ }^{75}$ y sólo con el objeto de impedirla se implementó esta cláusula en el ámbito constitucional, esperando que transcurrido el término de tres años, los montenegri-

69 Véase PARTos, Gabriel, "What next for Montenegro?", en BBC News, 22 de mayo de 2006, disponible en bttp://newsvote.bbc.co.uk/mpapps/pagetools/print/news.bbc.co.uk/2/hileurope/5005344.stm (consultada el día 23 de mayo de 2006).

70 "La Serbie reconnaît le Monténégro indépendant", en Le Monde, 15 de junio de 2006, disponible en http://www. lemonde.fr/ueblimprimer element/0,40-0,50-784145,0.html (consultada el 5 de julio de 2006).

71 Resolución 60/264 de la Asamblea General de Naciones Unidas, de 28 de junio de 2006, así como sus comentarios anexos, disponible en http://wwwu.un.org/News/Press/docs/2006/ga10479.doc.htm (consultada el día 30 de junio de 2006).

72 Véase supra nota 9.

73 Para un análisis de la cláusula constitucional de secesión en Etiopía, que tiene como presupuesto a sus grupos étnicos, véase HaBtu, Allem, "Multiethnic Federalism in Ethiopia: A Study of the Secession Clause in the Constitution", en Publius: The Journal of Federalism, Oxford Universiry Press, Volumen 35, No 2, Primavera 2005, pp. 313-358.

74 Véase, por ejemplo, Dérens, Jean - Arnault, "Lendemains Amers pour les Orphelins de la 'Grande Serbie”, en Le Monde Diplomatique, noviembre 1997, París, Francia, pp. 14-15.

75 Varios autores señalan que desde muchos años antes de la separación, Montenegro ya operaba como un Estado de facto en el marco de la Unión que formaba con Serbia, la que sólo era una especie de "cascarón internacional". Montenegro no poseía Ejército ni cuerpo diplomático, pero sí tenía un sistema fiscal propio, aduana y moneda distinta de la serbia, primero el marco alemán y luego el euro. Véase TrsLIK, Lee Hudson, Op. cit.; y Dérens, Jean - Arnault y Geslin, Laurent, Op. cit., p. 16. 
nos hubiesen desistido de ejercer este derecho, siempre dentro de su interpretación asociativista. Mas ello no sucedió. Por tanto, la cláusula constitucional de secesión no implica estar en presencia de un derecho remedio, sino que sólo tuvo por finalidad la dilatación del derecho entendido en el contexto de una teoría asociativa. El único mérito de esta constitucionalización radica en que estableció un procedimiento cierto para el ejercicio del derecho, lo que permitió garantizar su carácter pacífico, así como positivizar los principios de las teorías de la libre elección.

La constitucionalización del proceso tuvo también otra ventaja práctica: permitió una salida pacífica a las tensiones secesionistas montenegrinas, por medio del acuerdo político entre las distintas unidades del Estado, dando así lugar a un "divorcio de terciopelo", a semejanza del proceso vivido en la ex Checoslovaquia ${ }^{76}$. Incluso más, este acuerdo abrió el camino para el reconocimiento internacional brindado al nuevo Estado de Montenegro, acto discrecional que es tradicionalmente negado a los secesionistas.

¿Cuáles son las motivaciones montenegrinas para obtener la secesión? Éstas no han sido negadas siquiera oficialmente. Primeramente, gran parte de la población y de las autoridades de Montenegro estimaban que su relación con Serbia no les reportaba verdaderos beneficios, puesto que la economía del Estado común era débil y dirigida por los serbios, los cuales en cierto modo condenaban a Montenegro a vivir su mismo subdesarrollo. Además, la separación era vista paradójicamente como el medio más viable para lograr la integración con Europa. Serbia, dada su posición respecto de los criminales de guerra con su nacionalidad, ha generado un factor de rechazo en la Unión Europea, aun cuando ya ha tendido a promover su incorporación a ésta, la que se vislumbraba, desde antes de la secesión de Montenegro, como un proceso altamente dificultoso. Un Montenegro independiente tendría mayores posibilidades de integrarse rápidamente en la Unión Europea, prosperando así política y económicamente ${ }^{77}$. Por

76 La prensa lo ha denominado de este modo: "Le Monténégro va officiellement prononcer son Indepéndance" en Le Monde, 3 de junio de 2006. Además, acerca de las secesiones pacíficas, con especial referencia al caso checoslovaco, véase Young, Robert A., "How do Peaceful Secessions happen?", en Canadian Journal of Political Science / Revue Canadienne de Science Politique, Canadian Political Science Association, Volumen XXVII, No 4, diciembre 1994, pp. 773-792; Dion, Stéphane, "Why is Secession Difficult in Well - Established Democracies? Lessons from Quebec", en British Journal of Political Science, Cambridge University Press, Volumen 26, № 2, abril 1996, pp. 269-283; Heractides, Alexis, "Partition, Autonomy, Secession. The Three Roads of Separatism", en Cahiers d'Études sur la Méditerranée Orientale et le Monde Turco - Iranien (CEMOTI), № 34 (Russie - Asie Centrale. La Partition en Question), julio - diciembre 2002, pp. 149-175; STErn, Eric, "Peaceful Separation: 'A New Virus'?, en Columbia Journal of Transnational Law, Volumen 36, № 1 - 2, 1997, pp. 25-39; Massa, Salvatore, "Secession by Mutual Assent: A Comparative Analysis of the Dissolution of Czechoslovakia and the Separatist Movement in Canada", en Wisconsin International Law Journal, Volumen 14, No 1, 1995, pp. 183-222; y Osterland, Holly A., "National Self - Determination and Secession: The Slovak Model", en Case Western Reserve Journal of International Law, Volumen 25, 1993, pp. 655-702.

77 En este sentido, véase Jovanovic, Miodrag,"National Self - Determination as a Legitimate Way towards European Union - The Case of Former Yugoslavia", en International Journal on Minority and Group Rights, Kluwer Law International, Volumen 9, № 1, 2002, pp. 71-79. Por lo demás, especialmente llamativo parecer ser el proceso secesionista montenegrino para la Unión Europea. Además de fijar algunos parámetros en torno a la regulación pacífica de las separaciones al interior de Europa y del reconocimiento a entregar en tales casos, permite establecer mecanismos de desintegración política reafirmando la integración económica, con lo cual se hace más llevadera y 
último, Montenegro pasó, con tal acto de autodeterminación, a convertirse en un Estado con una relativamente amplia costa adriática, lo cual permite desechar, siquiera parcialmente, el argumento contrario serbio de un Estado montenegrino inviable (el cual parece motivado en el hecho de que, con la independencia de Montenegro, Serbia quedó en situación de mediterraneidad).

Las objeciones de Serbia fueron varias, ninguna lo suficientemente fuerte para prohibir la secesión en caso que los montenegrinos así lo decidiesen, cuestión que así sc presentó, lo que confirma la aplicación de las teorías asociativas de la secesión como derecho primario. Aparte de la inviabilidad del Estado, por su falta de recursos y de medios, además de su exigua población ${ }^{78}$, se agregaban los perjuicios que se causaría a los montenegrinos residentes en Serbia, que perderían su nacionalidad y quedarían apátridas, a menos que Montenegro les concediese ésta, sin olvidar que podrían llegar a perder sus trabajos, especialmente aquéllos que se desempeñaban como funcionartos públicos. A mi parecer, este argumento es infundado. Cualquier Estado liberal enfrentado a una secesión ha de otorgar a sus residentes el derecho de optar por la nacionalidad que decidan. Así, Montenegro no puede obligar a los montenegrinos residentes en el extranjero a integrarse al nuevo Estado (cuestión que además parece no querer, ya que les negó el derecho de sufragio en el referéndum de secesión), como tampoco Serbia puede forzarles a dejar su Estado privándoles de su nacionalidad. Los únicos que poseen derecho respecto de la determinación de su nacionalidad son los mismos afectados, quienes podrán oprar según lo estimen conveniente. Si se admitiese la idea que Montenegro puede forzar a los montenegrinos en el extranjero a integrarse en su Estado, ello significaría un cierto cruzamiento con las teorías adscriptivas, cuestión que no es apropiada, dados los puntos en contra que ya he indicado. Si se admite la segunda aiternativa, implicaría aceptar un derecho a la expulsión, el cual no guarda coherencia alguna con los principios liberales inherentes a toda secesión.

Por último, los argumentos serbios hacían referencia al efecto demostración que tendría la secesión montenegrina en Kosovo. Este es indudablemente un riesgo quc se debe afrontar en la teoría liberal asociativista. La recursividad de la secesión no sólo se evidencia en los Estados secesionistas, sino que también en el Estado que queda. La decisión libre de los individuos de Montenegro no puede ser limitada teniendo en consideración aspectos externos a su derecho, como serían las consecuencias que la separación tendría en el Fstado serbio. Si no se admite que la pérdida de sus costas sea argumento válido para negar la secesión, tampoco lo será la merma de otro

Facrible una eventual secesión ya no respecte de Estados fuera de la Linión, sitro incluso dentro de clla, como podráa suceder en el mediano plazo con las islas Feroe cn Dinamarca. Respecio de las demandas politicas secesiemistas foringias y la posiçión danęsa, véase Rógvi, Kári á, "The Iand of Maybe. A Survey of Faroese Consritutional History", ten Skat.F, Sjuturur (edicor). The Right to National Self-Determination. The Faroe Islands and Grenland. Nijholf Law Specials, Volumen 60. Koninklijke Brill NV, Martinus Nïghoff Publishers, Leiden, Paises Bajos, 2004, pp. 13-48.

" Basta con reiterar la presencía de múltiples miço-Estados al incerior de Fuscopa, plenamente reconocidos y aceprados, para descarar la validez de este argunento. 
territorio, la cual en cualquier caso no estará directamente supeditada a la separación montenegrina, sino que guardará relación, al menos en teoria, con los deseos de los mismos kosovares"

\section{Conclusiones}

La secesión de Montenegro es una excelente oportunidad de análisis de las teorías de la secesión en la praxis. Asombrosamente, según mi parecer, las teotias que menos adeptos parecen tener, vale decir las asociativas del derecho primario a la secesión, son las que inspiran el proceso secesionista cerrado este año, con la aparición de un nuevo Estado plenamente reconocido en la comunidad internacional.

El proceso montenegrino se fundó en la decisión libre de los montenegrinos, expresada en un momento histórico dado por medio de un referéndum, en orden a separarse del Estado del que formaban parte, puesto que ya no consentían a él. Por decirlo de otro modo, los montenegrinos se pronunciaron respecto de su retiro de una entidad política a la que consintieron en algún minuto, pero que ya no satisfacía sus necesidades. No se puede olvidar que el Estado tiene por principal función velar por los requerimientos de su población y permitirles desarrollarse tanto como sea posible. Si en el ejercicio de un derecho humano cono la libertad de asociación, los individuos deciden separarse, debido a que el Estado al que se hallan sujetos no cumple con sus perspectivas, nada puede impedirles hacerlo, ni siquiera el mismo Estado, argumentando con otros intereses que podrían ser opuestos a tal secesión.

Ésta es la posición sostenida por los secesionistas montenegrinos. $\mathrm{Ni}$ agravios ni pertenencia a un grupo de características definidas fueron exigidas para sostener la secesión y su legirimidad. Toda la validez del proceso se basó en la decisión libre de los montenegrinos, en igualdad de condiciones, sin distinguirles por raza, lengua o religión. El gobierno central se comportó como en un completo Estado liberal, lo cual no sólo permite destacar lo pacífico de esta secesión, sino que también la madurez que están alcanzando tímidamente las sociedades balcánicas. Es de esperar que dichos logros se vean afianzados en el futuro y no desechados como en otras ocasiones, con resultados nefastos no sólo para la región, sino que para el mundo entero.

I a creencia de que sólo la primera acción secesionista es la que impulsa codo proceso de esta especie implica negar toda auronomia a las posteriores acciones de orros subgrupos, cuyas secesiones pasarán a ser consideradas como simples actos reflejos generados por la primera. Respecto del efecto demostración en Kosovo, véase DéreNs, JEsN - Arnaulu r Gesion, Iaurent, Op. cit. pp. 17-18; y en general Redman, Michat, "Should Kosovo be Encited to Starehood!". en The Political Quarterly, Blackwell Publishers, Volumen 73, vio 3, julio 2002, pp. 338-343. 
